\title{
Immunhistochemical analysis of Nuclear Factor Kappa Beta expression in etiopathogenesis of ovarian tumors ${ }^{1}$
}

\author{
Ercan Yilmaz', Mehmet Gul", Rauf Melekoglu'", Isil Koleli'v
}

'Associate Professor, Department of Obstetrics and Gynecology, Faculty of Medicine, Inonu University, Malatya, Turkey. Manuscript writing.

"Full Professor, Department of Histology and Embriyology, Faculty of Medicine, Inonu University, Malatya, Turkey. Histopathological examinations.

"'Assistant Professor, Department of Obstetrics and Gynecology, Faculty of Medicine, Inonu University, Malatya, Turkey. Acquisition of data.

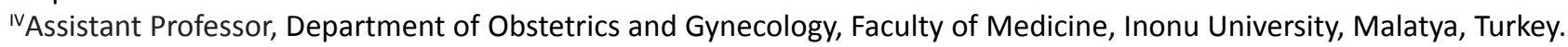
Statistical analysis.

\section{Abstract}

Purpose: To investigate the place of the transcription factor nuclear kappa B (NF-kB), which is a marker of chronic inflammation, in the etiology of the ovarian carcinoma.

Methods: NFkB analysis with the immunohistochemical method has been performed. To evaluate immunohistochemical NF-kB expression in the ovarian tissue, the H-score method. $\mathrm{H}$-score $=\sum \mathrm{Pi}(\mathrm{i}+1)$, where " $\mathrm{Pi}$ " is the percentage of stained cells in each intensity category $(0-100 \%)$ and " $i$ " is the intensity indicating weak ( $i=1)$, moderate ( $i=2)$ or strong staining ( $i=3)$. Results: It has been seen that, the mean $\mathrm{H}$ score is statistically significantly higher in the patient group with serous and musinous adenocarcinoma diagnosis than the two other patient groups $(p<0.005)$.

Conclusions: Factor nuclear kappa $B$ is an important mediator that acts in the chronic inflammation. The highest expression rates are determined by the immunohistochemical method in the ovarian cancer group.

Key words: NF-kappa B. Ovarian Neoplasms. Inflammation. Etiology. 


\section{- Introduction}

Although ovarian cancer is the second most frequently seen gynecologic tumor, epithelial ovarian cancers have the highest rates of mortality. Primary tumors of ovaries originate from germ cells, sex chord, stromal and superficial epithelial cells and ovarian tumors of epithelial origin constitute $95 \%$ of the entire group ${ }^{1,2}$. Especially epithelial ovarian cancers are diagnosed at a later stage when the tumor has already had distant metastases. This condition complicates treatment of the disease and decreases survival times below the expected ones ${ }^{3}$. Borderline ovarian tumors (BOT) is a definition independent from epithelial ovarian cancers, and it is firstly described in the year 1973 and constitutes nearly $15-20 \%$ of epithelial ovarian cancers ${ }^{4}$.

Inflammation is the most important cause in the pathophysiology of cancer tissue. Mediators released into the environment lead to cellular DNA damage, inhibition of apoptosis and development of angiogenesis which results in growth and progression of tumor cells and formation of metastases. It is well known that interleukin-6 (IL-6), which is increasingly synthesized during the chronic inflammation process, stimulates angiogenesis, the main factor in the local invasion and distant organ metastasis. It has been demonstrated that this effect depends on the increase of mRNA synthesis induced by the vascular endothelial growth factor (VEGF). The levels of C-reactive protein (CRP) (another important mediator) increases also during the inflammation and the invasion capacity of the tumor cells, which consequently induces the cancer development ${ }^{5}$.

In recent years mostly studied chronic inflammation mediator has been nuclear transcription factor-kappa beta (NF-kB) which at the same time controls cellular proliferation, apoptosis, angiogenesis, immune reaction, cellular adhesion and differentiation (NF-kB). NF-kB pathway plays an important role in the inflammation and carcinogenesis ${ }^{6}$. NF-kB family consists of different subunits as p50, p65 (RelA), c-Rel, RelB, p50, and p52. The most prevalently found subtype in human cells and all other mammalian species is p65/ p50 heterodimer structure which is found bound to intracytoplasmic inhibitor protein (IkB). Following internal gene mutation and/ or external stimulation IkB kinase enzyme is activated and translocated into inactive NF$k B$. As a consequence, it effects transcription genes with resultant stimulation of local and systemic inflammation leading indirectly to carcinogenesis ${ }^{7}$.

In this study, our objective was to discuss the place of the NF-kB, which is an important factor of the cancer etiopathogenesis and indirectly contributes to the inflammation and inflammatory mediators, in the etiology of the ovarian cancer.

\section{Methods}

\section{Patient selection}

Patients presented to our clinic were divided into 3 groups based on histopathology results as benign, malignant and borderline cases. Group 1 consisted of patients diagnosed as serous cystadenoma, Group 2 comprised of cases with borderline ovarian tumors and Group 3 included patients with a diagnosis of serous cystadenocarcinoma. Ethics Committee Approval is done (2016/14).

\section{Histopathologic diagnosis of ovarian tissues}

When cyst composed of bland epithelium resembling fallopian tube epithelium or surface epithelium of ovary; 
serous cystadenoma was diagnosed. Serous cystadenoma has flat cyst lining and smooth outer surface. Cyst lining varies from pseudostratified tubal epithelium to single layer of flattened to cuboidal cells without atypia or mitoses. The serous borderline tumor was diagnosed when a cyst has fine, friable and exuberant papillary projections lining inner cyst walls and cells resemble those in benign serous tumors, extensive epithelial stratification, and tufting with a detachment of individual cells and cell clusters. But typically multilocular, cystic and solid with soft, friable papillae filling cyst cavity containing serous bloody fluid and hemorrhage and necrosis was seen in serous carcinoma. Invasive serous carcinoma was composed of neoplastic cells resembling those of fallopian tube epithelium and architecture varies from papillary to glandular to solid to complex papillary architecture.

The benign mucinous tumor was diagnosed when cyst lined by bland, nonstratified mucinous gastrointestinal-type epithelium. If glands lined by mild to moderately atypical gastrointestinal-type mucinous cells with variable nuclear stratification, tufting or filiform papillae;Mucinous Borderline Tumor was diagnosed. If cyst lined highly atypical gastrointestinal-type mucinous cells and confluent glandular expansile pattern of invasion with markedly crowded glands with little intervening stroma; Mucinous Carcinoma was diagnosed.

\section{Ovarian samples for immunohistochemical labeling of NF-kappa B/65 (RelA) Ab-1}

There are five different members of the NF-kB subunit family: p50, p65 (Rel A), c-Rel, RelB, p50, and p52. These proteins form homo- and heterodimers, with the classic NF$k B$ heterodimer containing p50 and p65. Of these members of the NF-kB family, the p65 subunit is able to activate the transcription of target genes. Therefore, in the current study, a specific kit containing antibodies against the p65 subunit of NF-kB was used to detect the level of activated NF-kB in endometrial samples.

Samples for immunohistochemical assay were obtained four-micrometer paraffin sections on poly-L-lysine coated slides were dried in an oven for one $h$ at $60^{\circ} \mathrm{C}$. The sections were then dewaxed in xylene, rehydrated in ethanol and then incubated for $10 \mathrm{~min}$ in 3\% $\mathrm{H}_{2} \mathrm{O}_{2}$ to block endogenous peroxidase. After washing in phosphate buffer saline (PBS), the sections were incubated for $8 \mathrm{~min}$ in Ultra $\mathrm{V}$ Block. The immunoreaction was performed for 60 min with ready to use NF KappaB/p65 (Rel A) Ab-1antibody (NeoMarkers, Labvision Corp., Fremont, CA, anti-NFkB p65, polyclonal PA 138279). After washing in PBS, slides were incubated with horse radish peroxidase (HRP) kit. Finally, the preparations were developed in AEC (3-amino-9-ethylcarbazole) chromogen counterstained with hematoxylin and mounted with aqueous-mount. To evaluate immunohistochemical NF-kB expression in the ovarian tissue, the $\mathrm{H}$-score method introduced by Budwit-Novotny et al. ${ }^{8}$ was used. This semiquantitative method consists of summing the percentages of positively stained cells and multiplying this by a weighted intensity of staining: $\mathrm{H}$-score $=\sum \mathrm{Pi}(\mathrm{i}+1)$, where " $\mathrm{Pi}$ " is the percentage of stained cells in each intensity category (0-100\%) and " $\mathrm{i}$ " is the intensity indicating weak $(\mathrm{i}=1)$, moderate $(\mathrm{i}=2)$ or strong staining $(i=3)$.

\section{Statistical analysis}

The SPSS 15.0 program was used for the statistical analyses. The values were expressed as a mean \pm standard deviation (SD) 
whenever appropriate. Categorical variables were reported as a number and a percent. Normally distributed variables were compared by one-way ANOVA test, whereas KruskalWallis test were used to compare the nonnormally distributed variables between the groups. For multiple comparisons of groups, Tukey and Conover tests were used where appropriate.

\section{Results}

Our study participants were divided into three different groups based on their histopathology results. Group 1 consisted of 9 patients with the diagnosis of serous cystadenoma. Group 2 comprised of a total ten patients with a diagnosis of borderline ovarian tumor. In this group 9 patients were diagnosed as serous and the remaining patient was diagnosed as a mucinous borderline ovarian tumor. Group 3 contained eight patients diagnosed as serous carcinoma $(n=6)$ and mucinous carcinoma $(n=2)$.

The mean age of the patients was $52.03 \pm 12.56$ years and three groups did not differ significantly with respect to patient ages. All patients in Group 1 underwent a total abdominal hysterectomy and bilateral salpingo-oophorectomy (TAH+BSO). Ten patients diagnosed as borderline ovarian tumor underwent combined TAH+BSO $(n=7)$, pelvic-paraaortic lymphadenectomy (PPLND) and omentectomy or unilateral salpingo-oophorectomy (USO), PPLND and contralateral ovarian biopsy $(n=1)$ or USO, contralateral ovarian and multiple peritoneal biopsies and PPLND $(n=1)$, while the remaining patient underwent only USO and multiple peritoneal biopsy procedures. All patients were evaluated as FIGO stage 1 and during postoperative follow-up chemotherapy was not required.

$$
\text { Cytoreductive surgery (tumoral }
$$
excision leaving $<1 \mathrm{~cm}$ tumor tissue intact) was performed for 4 of 8 patients diagnosed as an epithelial ovarian tumor. Four patients in this group underwent $\mathrm{TAH}+\mathrm{BSO}$, PPLND, omentectomy and appendectomy $(n=2), \quad T A H+B S O$, omentectomy, PPLND, peritonectomy and splenectomy $(n=1)$ and TAH+BSO, PPLND and omentectomy $(n=1)$ According to FIGO classification; the patients were categorized as Stage IIIC $(n=7)$ and stage $1 \mathrm{C}(\mathrm{n}=1)$. All of the patients received six courses of adjuvant paclitaxel and carboplatin treatment. Five patients diagnosed as epithelial ovarian tumor underwent intraoperative hyperthermic chemotherapy (HIPEC). Characteristics of the patients participated in the study are summarized in Table 1 . The assessment of immunostaining for NF-kB was made by using the $\mathrm{H}$-score method. In the calculation of an H-score, a summation of the percentage of area stained at each intensity level multiplied by the weighted intensity of staining is generated. In Group 1 which consists of patients with the diagnosis of serous cystadenoma estimated mean $\mathrm{H}$-score was $127.7 \pm 48.4$ points, while mean $\mathrm{H}$ scores of Group 2 with borderline tumors and of Group 3 with epithelial ovarian tumors were $166.0 \pm 95.5$ and $311.2 \pm 80.2$ points, respectively. When intergroup NF-kB positivity was evaluated using immunohistochemical method, statistically significantly higher $\mathrm{H}$ score was detected in Group 3 consisting of patients with the diagnosis of serous or mucinous epithelial carcinoma $(p<0.001)$ (Table 2). 
Table 1 - Characteristics of the patients participating in the study.

\begin{tabular}{|c|c|c|c|c|c|c|c|}
\hline $\begin{array}{l}\text { Patient } \\
\text { № }\end{array}$ & Age & Pathology & Surgery Performed & $\begin{array}{l}\text { PLND } \\
\text { (n) }\end{array}$ & $\begin{array}{l}\text { PALND } \\
\text { (n) }\end{array}$ & Stage* & Chemoteraphy \\
\hline 1 & 81 & Serous cystadenoma & $\mathrm{TAH}+\mathrm{BSO}$ & & & & \\
\hline 2 & 62 & Serous cystadenoma & $\mathrm{TAH}+\mathrm{BSO}$ & & & & \\
\hline 3 & 70 & Serous cystadenoma & $\mathrm{TAH}+\mathrm{BSO}$ & & & & \\
\hline 4 & 56 & Serous cystadenoma & $\mathrm{TAH}+\mathrm{BSO}$ & & & & \\
\hline 5 & 54 & Serous cystadenoma & $\mathrm{TAH}+\mathrm{BSO}$ & & & & \\
\hline 6 & 62 & Serous cystadenoma & $\mathrm{TAH}+\mathrm{BSO}$ & & & & \\
\hline 7 & 48 & Serous cystadenoma & $\mathrm{TAH}+\mathrm{BSO}$ & & & & \\
\hline 8 & 54 & Serous cystadenoma & $\mathrm{TAH}+\mathrm{BSO}$ & & & & \\
\hline 9 & 59 & Serous cystadenoma & $\mathrm{TAH}+\mathrm{BSO}$ & & & & \\
\hline 10 & 50 & $\begin{array}{l}\text { Serous borderline } \\
\text { tumor }\end{array}$ & $\begin{array}{l}\text { TAH+BSO PPLND } \\
\text { Omentectomy }\end{array}$ & 14 & 12 & IA & \\
\hline 11 & 41 & $\begin{array}{l}\text { Serous borderline } \\
\text { tumor }\end{array}$ & $\begin{array}{l}\text { TAH+BSO PPLND } \\
\text { Omentectomy }\end{array}$ & 18 & 16 & IA & \\
\hline 12 & 27 & $\begin{array}{l}\text { Serous borderline } \\
\text { tumor }\end{array}$ & $\begin{array}{l}\text { TAH+BSO PPLND } \\
\text { Omentectomy }\end{array}$ & 7 & 6 & IA & \\
\hline 13 & 26 & $\begin{array}{l}\text { Serous borderline } \\
\text { tumor }\end{array}$ & $\begin{array}{l}\text { TAH+BSO PPLND } \\
\text { Omentectomy }\end{array}$ & 12 & 18 & & \\
\hline 14 & 45 & $\begin{array}{l}\text { Serous borderline } \\
\text { tumor }\end{array}$ & $\begin{array}{l}\text { TAH+BSO PPLND } \\
\text { Omentectomy }\end{array}$ & 11 & 6 & & \\
\hline 15 & 50 & $\begin{array}{l}\text { Serous borderline } \\
\text { tumor }\end{array}$ & $\begin{array}{l}\text { TAH+BSO PPLND } \\
\text { Omentectomy }\end{array}$ & 19 & 13 & IA & \\
\hline 16 & 50 & $\begin{array}{l}\text { Serous borderline } \\
\text { tumor }\end{array}$ & $\begin{array}{l}\text { TAH+BSO PPLND } \\
\text { Omentectomy }\end{array}$ & 11 & 13 & IA & \\
\hline 17 & 43 & $\begin{array}{l}\text { Serous borderline } \\
\text { tumor }\end{array}$ & $\begin{array}{l}\text { USO+PPLND Contralateral } \\
\text { ovarian biopsy }\end{array}$ & 16 & 21 & IA & \\
\hline 18 & 46 & $\begin{array}{l}\text { Serous borderline } \\
\text { tumor }\end{array}$ & $\begin{array}{l}\text { USO+PPLND Contralateral } \\
\text { ovarian biopsy+multipl } \\
\text { peritoneal biopsy }\end{array}$ & 18 & 17 & IA & \\
\hline 19 & 47 & $\begin{array}{l}\text { Serous borderline } \\
\text { tumor }\end{array}$ & USO+multipl peritoneal biopsy & & & IA & \\
\hline 20 & 32 & Serous carcinoma & $\begin{array}{l}\text { TAH+BSO PPLND Omentectomy } \\
\text { Peritonektomi Splenectomy HIPEC }\end{array}$ & 36 & 40 & IIIC & Paclitaxel Carboplatin \\
\hline 21 & 70 & Serous carcinoma & $\begin{array}{l}\text { TAH+BSO PPLND Omentectomy } \\
\text { Appendectomy }\end{array}$ & 12 & 8 & IIIC & Paclitaxel Carboplatin \\
\hline 22 & 65 & Mucinous carcinoma & $\begin{array}{l}\text { TAH+BSO PPLND Omentectomy } \\
\text { Appendectomy }\end{array}$ & 14 & 12 & IC & Paclitaxel Carboplatin \\
\hline 23 & 56 & Serous carcinoma & Cytoreductive surgery HIPEC & 12 & 9 & IIIC & Paclitaxel Carboplatin \\
\hline 24 & 42 & Serous carcinoma & TAH+BSO PPLND Omentectomy & 10 & 14 & IIIC & Paclitaxel Carboplatin \\
\hline 25 & 58 & Serous carcinoma & Cytoreductive surgery HIPEC & 24 & 19 & IIIC & Paclitaxel Carboplatin \\
\hline 26 & 52 & Mucinous carcinoma & Cytoreductive surgery HIPEC & 22 & 18 & IIIC & Paclitaxel Carboplatin \\
\hline
\end{tabular}

TAH+BSO. total abdominal hysterectomy+bilateralsalpingo-oophorectomy; PPLND. pelvic-paraaortic lymphadenectomy; PLND. pelvic lymphadenectomy; PALND. paraaortic lymphadenectomy; USO. unilateral salpingo-oophorectomy; HIPEC. hyperthermic intraperitoneal chemotherapy; cytoreductive surgery. surgical procedure performed leaving less than $1 \mathrm{~cm}$ margin of tumoral tissue intact; Stage*. Based on FIGO 2009 staging system. 
Table 2 - Intergroup comparison of $\mathrm{H}$ scores, $\mathrm{p}<0.05$ was accepted as the level of statistical significance.

\begin{tabular}{lll}
\hline Patient Groups & H score & p value \\
\hline Group 1 (Serous cystadenoma, $\mathbf{n = 9}$ ) & $127.7 \pm 48.4$ & \\
Group $\mathbf{2}$ (Serous-mucinous borderline tumor, $\mathbf{n = 1 0}$ ) & $166.0 \pm 95.5$ & \\
Group $\mathbf{3}$ (Serous-mucinous cystadenocarcinoma, $\mathbf{n = 8}$ & $311.2 \pm 80.2$ & $<0.001$ \\
\hline
\end{tabular}

When the images from the light microscope of the immunohistochemical results of our study were examined, it was seen that cytoplasmic and/nuclear NF-kB expression was more apparent in the group diagnosed with ovarian cancer compared to the other two groups (Figure 1).

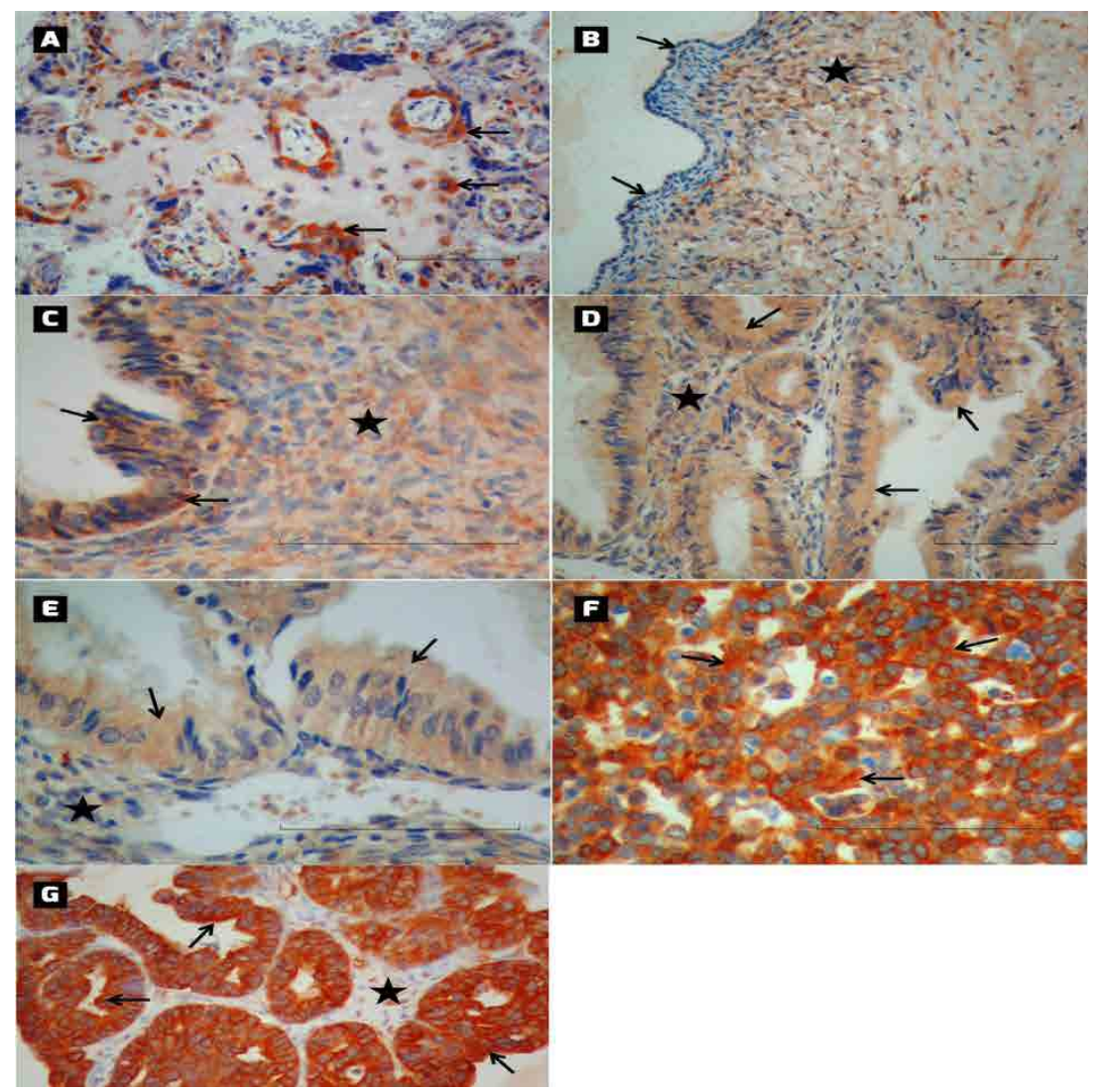

Figure 1 - A. Positive Control; Human plasenta. Immunohistochemical positive immunoreactivity of NF-kB (arrow). IHC, x20. B. Serous cystadenoma; Epithelial (arrows) and stromal (aster) immunohistochemical positive immunoreactivity of NF-kB. IHC, x20. C. Serous cystadenoma; Epithelial (arrows) and stromal (aster) immunohistochemical positive immunoreactivity of NF-kB. IHC, x40. D. Borderline; Epithelial (arrows) and stromal (aster) immunohistochemical positive immunoreactivity of NF-kB. IHC, x20. E. Borderline; Epithelial (arrows) and stromal (aster) immunohistochemical positive immunoreactivity of NF-kB. IHC, x40. F. Serousmucinous carcinoma; Diffuse immunohistochemical positive immunoreactivity (arrows) of NF-kB. IHC, x20. G. Serous-mucinous carcinoma; Epithelial (arrows) and stromal (aster) immunohistochemical positive immunoreactivity of NF-kB. IHC, x40. 


\section{- Discussion}

Tumors developing from ovarian tissue have been classified as germ cell, sex chord stromal and epithelial cell tumors, epithelial ovarian cancers have become an important health problem, and because they are diagnosed at a late stage when they had distant organ metastases and being the most fatal female genital system cancer, they threaten patient health significantly. In the whole world, nearly $2 / 3$ of the newly diagnosed 240.000 cases lose their lives ${ }^{8}$. However, borderline ovarian tumors consist $15-20 \%$ of all epithelial ovarian tumors. They were firstly defined by International Federation of Gynecology and Obstetrics (FIGO) in the year 1973 and classified as a tumor with low malignant potential. Although its definition bases on totally histopathological findings, epithelial cell proliferation without stromal invasion is the gold standard in the establishment of the diagnosis of the borderline tumor ${ }^{9}$.

Although many different causes have been described in the etiology of ovarian cancer, chronic inflammation is an important factor in the etiology of both epithelial and also borderline ovarian tumors. Regular cycles of ovulation cause chronic inflammation which increases cytokine secretion leading to an acceleration of cellular mitosis, apoptotic errors, and development of malignant transformation ${ }^{10}$. In many literature studies significantly higher levels of some proinflammatory cytokines (i.e., interleukin 2-4-6-12 and 13) have been detected in follicular fluids of patients diagnosed as ovarian tumor when compared with the control group ${ }^{11}$. However, the mechanism in which increased cytokine secretion induces carcinogenesis in ovarian tissue has not been clarified yet. This challenging condition requires demonstration of different intracellular mechanisms which explain the etiological role of inflammation in carcinogenesis. The importance of estrogen in the etiology of ovarian carcinoma should not be forgotten. In their study, Perniconi et al. ${ }^{12}$ determined that dysmorphological changes emerged in the ovarian superficial epithelium in rats, which received high dose estrogen. It was also demonstrated that inflammatory mediators were responsible for the effect of estrogen. The increased mitogenic activity stimulated the synthesis of the growth factors and cytokines. Bcl-2, c-Myc proto-oncogene, $\alpha$-TGF and IL- 6 levels increased during the estrogen-depended increase of mitosis. These mediators were also responsible for tumorigenesis due to the stimulation of the cell proliferation and apoptosis.

To this end, in recent years mostly studied chronic inflammation mediator is nuclear transcription factor-kappa beta (NF$\mathrm{kB}$ ) which at the same time controls cellular proliferation, apoptosis, angiogenesis, immune reaction, cellular adhesion and differentiation $(\mathrm{NF}-\mathrm{kB})^{13}$. NF-kB pathway plays a very important role in inflammation and carcinogenesis ${ }^{14}$. NF-kB family consists of different subunits as p50, p65 (RelA), c-Rel, RelB, p50, and p52. The most prevalently found subtype in human cells and all other mammalian species is p65/ p50 heterodimer structure which is found bound to intracytoplasmic inhibitor protein (IkB). Following internal gene mutation and/ or external stimulation IkB kinase enzyme is activated, translocated into inactive NF$\mathrm{kB}$. As a consequence, it effects transcription genes with resultant stimulation of local and systemic inflammation leading indirectly to carcinogenesis?.

Many studies have been performed which explained the association between NF$\mathrm{kB}$ activation and cancerogenesis. Mosialos et al. indicated that established effectiveness of Ebstein-Barr virus in the etiopathogenesis of Burkitt and Hodgkin lymphoma is exerted through activation of NF-kB ${ }^{15}$. Still increased 
NF-kB activation at a cellular level was demonstrated in cases with Hodgkin's lymphoma which displayed extranodal spread $^{16}$. Nagel et al. ${ }^{18}$ demonstrated higher NF-kB activity in cases with hairy cell leukemia 17. In another study where 33 patients with colorectal cancer, increased NF-kB activation was demonstrated in patients with established diagnosis of malignancy. Zhao et al. ${ }^{19}$ demonstrated increased NF-kB activation in patients diagnosed as papillary thyroid carcinoma.

When studies investigating gynecologic tumors and NF-kB expression are reviewed, publications supporting our study have striked our attention. In a study which consisted of 63 patients diagnosed as epithelial ovarian cancer, a direct correlation was detected between increased NF-kB expression, chemoresistant disease and lymph node metastasis ${ }^{20}$. Chen et al. ${ }^{21}$ compared outcomes of 411 patients with epithelial ovarian tumor and healthy 438 patients and demonstrated significantly higher NF-kB expression in the tissues of the patients with established diagnosis of malignancy. Although the presence of a viral effect in the etiology of cervical cancer has been indisputably accepted, in recent years the significant role of NF-kB expression in the development of cervical cancer has been also demonstrated. In a study where 240 cervical cancer tissue and 290 normal cervical tissue specimens were investigated, higher NF-kB expression has been demonstrated in patients with the diagnosis of cervical cancer ${ }^{22}$. Nakahara et $a .^{23}$ displayed that contamination with Human Papilloma Virus (HPV) type-16 which is the most important agent in the etiology of cervical cancer increases NF-kB expression which consequently stimulates persistence of HPV infection. Review of the studies which investigated the correlation between NF-kB and endometrial cancer have yielded similar results. Various studies have demonstrated that IL-6 cytokine which induces cellular proliferation, exerts this effect by indirectly enhancing NF-kB expression ${ }^{24}$. In a study where NF-kB expression was investigated in in vitro cell cultures using Western blot technique, increased NF-kB expression was observed in cancer cells ${ }^{25}$.

The importance of the chronic inflammation and of the cytokines and inflammatory markers, which are increasingly secreted from the inflammatory cells, is well known. These cytokines cause direct DNA damage and, in addition, contribute to the tumorigenesis due to the indirect inhibition of the apoptosis and stimulation of angiogenesis. In the estrogen-dependent ovarian carcinoma, the levels of the inflammatory markers increase under the influence of estrogen. The importance of these mediators is well known in the etiology of the ovarian carcinoma, which is considered as a secondary development to the dysmorphology that emerges at the cellular level in the superficial epithelium.

\section{- Conclusions}

Factor nuclear kappa B is an important mediator that acts in the chronic inflammation. The highest expression rates are determined by the immunohistochemical method in the ovarian cancer group.

\section{- References}

1. Chandrashekhara SH, Triveni GS, Kumar R. Imaging of peritoneal deposits in ovarian cancer: a pictorial review. World J Radiol. 2016; :513-7. dol: 10.4329/wjr.v8.i5.513.

2. Cannistra SA. Cancer of the ovary. N Eng J Med. 2004;351:2519-29. doı: 10.1056/ NEJMra041842.

3. De Angelis R, Sant M, Coleman MP, Rancisci $S$, Baili $P$, Pierannunzio D, Trama A, Visser $\mathrm{O}$, Brenner $\mathrm{H}$, Ardanaz E, Bielska-Lasota $\mathrm{M}$, Engholm G, Nennecke A, Siesling S, Berrino F, Capocaccia R. Cancer survival in Europe 
1999-2007 by country and age: results of EUROCARE-5 a population-based study. Lancet Oncol. 2014;15:23-34. dol: 10.1016/ S1470-2045(13)70546-1.

4. Cosyns S, Polyzos NP, Carprieaux M, Carprieaux M, Tournaye $H$, De Sutter P. The role of appendectomy as part of the treatment of a mucinous borderline ovarian tumor. Eur J Gynaecol Oncol. 2016;37:16770. PMID: 27172739.

5. Kim DK, Oh SY, Kwon HC, Lee S, Kwon KA, Kim BG. Kim SH, Jang JS, Kim MC, Kim KH, Han JY, Kim HJ. Clinical signifi cances of preoperative serum interleukin-6 and C-reactive protein level inoperable gastric cancer. BMC Cancer. 2009;9:155-9. dol: 10.1186/1471-2407-9-155.

6. Karin M, Cao Y, Greten FR, Li ZW. NF-kappaB in cancer: from innocent bystander to major culprit. Nat Rev Cancer. 2002;2:301-10. doI: 10.1038/nrc780.

7. Chen $Y$, Lu R, Zheng $H$, Xiao R, Feng J, Wang $\mathrm{H}$, Gao X, Guo L. The NFKB1 polymorphism (rs4648068) is associated with the cell proliferation and motility in gastric cancer. BMC Gastroenterol. 2015;15:1-12. dol: 10.1186/s12876-015-0243-0.

8. Ataseven B, Chiva LM, Harter P, GonzalezMartin A, du Bois A. FIGO stage IV epithelial ovarian, fallopian tube and peritoneal cancer revisited. Gynecol Oncol. 2016;1-11. dol: 10.1016/j.ygyno.2016.06.013.

9. Tropé CG, Kaern J, Davidson B. Borderline ovarian tumors. Best Pract Res Clin Obstet Gynaecol. 2012;26:325-36. dol: 10.1016/j. bpobgyn.2011.12.006.

10.Clendenen TV, Lundin $E$, ZeleniuchJacquotte $A$, Koenig KL, Berrino F, Lukanova A, Lokshin AE, Idahl A, Ohlson N, Hallmans G, Krogh V, Sieri S, Muti P, Marrangoni A, Nolen BM, Liu M, Shore RE, Arslan AA. Circulating inflammation markers and risk of epithelial ovarian cancer. Cancer Epidemiol Biomarkers Prev2011;20:799-810. dol: 10.1158/1055-9965.EPI-10-1180.

11.Wang YQ, Jin C, Zheng HM, Zhou K, Shi BB, Zhang $Q$, Zheng FY, Lin F. A novel prognostic inflammation score predicts outcomes in patients with ovarian cancer. Clin Chim Acta. 2016; 456:163-9. doI: 10.1016/j. cca.2016.03.013.

12.Perniconi SE, Simões Mde J, Simões Rdos S, Haidar MA, Baracat EC, Soares JM Jr. Proliferation ofthe superficial epithelium of ovaries in senile female rats following oraladministration of conjugated equine estrogens. Clinics (Sao Paulo). 2008;63:3818. PMID: 18568250.

13.Chen CD, Sawyers CL. NF-kappa B activates prostate-specific antigen expression and is upregulated in androgen-independent prostate cancer. Mol Cell Biol. 2002;22:286270. PMID: 11909978.

14. Karin M, Cao Y, Greten FR, Li ZW. NF-kappa B in cancer: from innocent bystander to major culprit. Nat Rev Cancer. 2002;2:301-10. doI: 10.1038/nrc780.

15.Mosialos G. The role of Rel/NF-kappa $B$ proteins in viral oncogenesis and the regulation of viral transcription. Semin Cancer Biol. 1997;8:121-9. dol: 10.1006/ scbi.1997.0063.

16.Dolcet X, Llobet D, Pallares J, Matias-Guiu $\mathrm{X}$. NF-kB in development and progression of human cancer. Virchows Arch. 2005;446:475-82. dol: 10.1007/s00428005-1264-9.

17. Nagel S, Ehrentraut S, Meyer C, Kaufmann $M$, Drexler HG, MacLeod RA. NFkB is activated by multiple mechanisms in hairy cell leukemia. Genes Chromosomes Cancer. 2015;54:418-32. doI: 10.1002/gcc.22253.

18. Hai Ping P, Feng Bo T, Li L, Nan Hui Y, Hong Z. IL-1B/NF-kb signaling promotes colorectal cancer cell growth through miR-181a/PTEN axis. Arch Biochem Biophys. 2016;604:20-6. dol: 10.1016/j.abb.2016.06.001.

19.Zhao S, Wang Q, Li Z, Ma X, Wu L, Ji H, Qin G. LDOC1 inhibits proliferation and promotes apoptosis by repressing NF-kB activation in papillary thyroid carcinoma. J Exp Clin Cancer Res. 2015;34: 1-12. dol: 10.1186/ s13046-015-0265-z.

20.Shuang T, Wang $M$, Zhou $Y$, Shi C. Overexpression of nuclear NF-kB1 and c-Rel correlates with chemoresistance and prognosis of serous epithelial ovarian cancer. Exp Mol Pathol. 2016;100:139-44. dol: 10.1016/j.yexmp.2015.11.030.

21.Chen LP, Cai PS, Liang HB. Association of the genetic polymorphisms of NFKB1 with susceptibility to ovarian cancer. Genet Mol Res. 2015;14:8273-82. dol: 10.4238/2015. July.27.15.

22.Pallavi S, Anoop K, Showket $H$, Alo N, Mausumi B. NFKB1/NFKBla polymorphisms are associated with the progression 
of cervical carcinoma in HPV-infected postmenopausal women from rural area. Tumour Biol. 2015;36:6265-76. doı: 10.1007/s13277-015-3312-7.

23.Nakahara T, Tanaka K, Ohno S, Egawa $\mathrm{N}$, Yugawa T, Kiyono T. Activation of NFKB by human papillomavirus 16 E1 limits E1-dependent viral replication through degradation of E1. J Virol. 2015;89:5040-59. doI: 10.1128/JVI.00389-15.

24.Che Q, Liu BY, Wang FY, He YY, Lu W, Liao
Y, Gu W, Wan XP. Interleukin 6 promotes endometrial cancer growth through an autocrine feedback loop involving ERK-NF$\mathrm{KB}$ signaling pathway. Biochem Biophys Res Commun. 2014;446:167-72. dol: 10.1016/j. bbrc.2014.02.080.

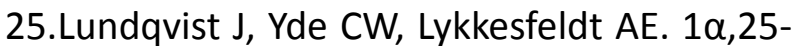
dihydroxyvitamin D3 inhibits cell growth and NFKB signaling in tamoxifen-resistant breast cancer cells. Steroids. 2014;85:30-5. dol: 10.1016/j.steroids.2014.04.001.

\section{Correspondence:}

\section{Ercan Yilmaz}

Department of Obstetrics and Gynecology,

Faculty of Medicine Inonu University, Malatya Turkey

Phone: +0905369556180

ercanyilmazgyn@yahoo.com

Received: Mar 08, 2018

Review: May 05, 2018

Accepted: June 04, 2018
Conflict of interest: none

Financial source: none
${ }^{1}$ Research performed at Histology and Embryology Laboratory, Department of Obstetrics and Gynecology, Faculty of Medicine, Inonu University, Malatya, Turkey. 